\title{
Improving Barrier Properties of PET by Depositing a Layer of DLC Films on Surface
}

\author{
Zhiguo Zhang, ${ }^{1}$ Riheng Song, ${ }^{2}$ Guoneng Li, ${ }^{1}$ Guilin Hu, ${ }^{1}$ and Yaoyu Sun ${ }^{1}$ \\ ${ }^{1}$ School of Light Industry, Zhejiang University of Science and Technology, Liuhe Road No. 318, Hangzhou, Zhejiang 310023, China \\ ${ }^{2}$ Department of Packaging Engineering, Xian University of Technology, Xian, Shanxi 710048, China
}

Correspondence should be addressed to Zhiguo Zhang; 107023@zust.edu.cn

Received 20 January 2013; Revised 10 April 2013; Accepted 20 May 2013

Academic Editor: Steve Bull

Copyright (c) 2013 Zhiguo Zhang et al. This is an open access article distributed under the Creative Commons Attribution License, which permits unrestricted use, distribution, and reproduction in any medium, provided the original work is properly cited.

The diamond-like carbon films (DLC films) depositing on the Poly (ethylene terephthalate) (PET) surface are obtained by plasmaenhanced chemical vapor deposition (PECVD), and the working gases are acetylene and argon gas. Surface morphology and the internal structure of DLC films are investigated by using Raman and FESEM, and the barrier properties of PET films which have been deposited the DLC films are tested in this paper. The results show that the deposition process parameters have an important effect on structure and performance of DLC films. It is shown that the diamond-like carbon films prepared by PECVD system are an amorphous carbon films which mixed with $s p 3$ bond and $s p 2$ bond. The best oxygen barrier property and water vapor barrier property of PET films are increased by 11 times and 12 times, respectively, in which the $I_{D} / I_{G}$ ratio of the DLC film is nearly 0.76 , and the sp3 content is about $40 \%$.

\section{Introduction}

Poly(ethylene terephthalate) (PET) is a thermoplastic polymer resin of the polyester family and is used in synthetic fibers; beverage, food, and other liquid containers; thermoforming applications; and engineering resins often in combination with glass fiber. PET bottles are widely used in drinks, fruit juices, medicines, and food packaging. However, PET material has the poor barrier properties compared with metal containers and glass containers. The life time of products with the PET container would be shorten due to the poor barrier properties, so many products cannot be packaged by PET container, for example, beer. In order to get a higher barrier property, the most widely adopted practice is to use aluminum foil or other composite material as functional barrier materials. However, the aluminum foil packaging material needs lots of energy consumption in the production process. The shortcoming is contrary to people's growing pursuit of environmental protection requirements, so people have been looking for the environment-friendly packaging materials.

Depositing a layer of the diamond-like carbon films (DLC films) on PET by plasma-enhanced chemical vapor deposition method is a new technology to improve PET barrier properties $[1,2]$. The DLC film is a kind of amorphous carbon films, and its network structure constitutes by $s p 3$ and $s p 2$ hybridized carbon atoms. Comparing with other packaging materials such as metals and silicon oxide composite materials, the DLC films is a new packaging barrier material which has a high atom density [3] this new amorphous carbon film has the advantage of optical transparency, gas barrier properties, environmental friendly, and mechanical strength. Due to the excellent performance of the DLC films, it has been widespread concerned all over the world, especially in the packaging materials field. The DLC films depositing on the substrate surface are generally obtained by using the plasma-enhanced chemical vapor deposition (PECVD) technology. In the PECVD technology, the deposition time, the radio-frequency power (RF power), the gas flow rate, and Ar fraction have an impact on the DLC films [4-6].

The research on DLC films are involved in many aspects because of its good performance. The barrier properties and the influence of different film-forming process on the barrier properties of DLC films are studied by many researchers [712]. Meanwhile, some researchers have taken much attention on study the DLC films-formation technology [13-16]. In 


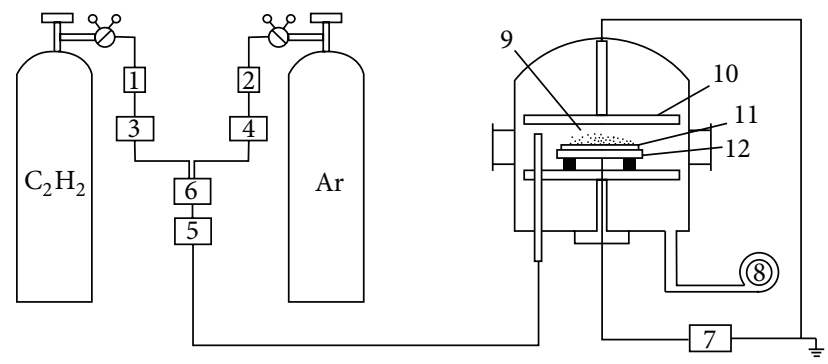

FIGURE 1: PECVD schematic diagram 1,2-regulators cans; 3,4,5-flow meter; 6-mixing chamber; 7-RF power; 8-vacuum pump; 9- $\mathrm{C}_{2} \mathrm{H}_{2}$ and Ar-mixed plasma gas; 10 -upper plate; 11-sample; 12 -lower plate.

addition to the studying on DLC films-forming technology and the impact on the barrier properties, more research works focus on the DLC films surface morphology and internal structure. Atomic force microscope (AFM) and scanning electron microscopy (SEM) are used to observe the surface morphology of the deposited film, and laser Raman spectroscopy (Raman), Fourier transform infrared spectroscopy (FTIR), and X-ray photoelectron spectroscopy (XPS) are used to characterize the composition and bonding structure of deposited films. In the literatures [17-20] the authors used different analytical methods to characterize the DLC films and structure.

In this paper, the diamond-like carbon films (DLC films) depositing on the Poly (ethylene terephthalate) (PET) surface are obtained by using the plasma-enhanced chemical vapor deposition (PECVD) technology to improve its barrier properties. The oxygen barrier property and water vapor barrier property of PET films are tested by VAC-V2 Gas Permeability Tester and W330 water vapor permeability tester. The surface morphology of DLC films is observed by using the Field Emission Scanning Electron Microscope (FESEM). The internal structure of DLC films are analyzed by using the laser Raman spectroscopy (Raman).

\section{Experiment}

2.1. Sample Preparation. The substrate material is PET, and its thickness is $0.1 \mathrm{~mm}$. DLC films deposited by plasmaenhanced chemical vapor deposition (PECVD), and the schematic diagram of PECVD is shown in Figure 1. The gas sources through a mixing vessel are a mixture of $\mathrm{C}_{2} \mathrm{H}_{2}$ and $\mathrm{Ar}$, and different gas concentration ratio is adjusted according to various gas partial pressures. The different deposition process parameters are shown in Table 1.

2.2. Analysis Methods. The microstructure composition of DLC films are characterized by using LabRam HR laser Raman spectroscopy (Raman) and laser scanning area is $1000 \sim 2000 \mathrm{~cm}^{-1}$. The surface morphology of DLC films are observed by using SIRION type field emission scanning electron microscope (FESEM).
TABLE 1: Deposition process parameters.

\begin{tabular}{lcccc}
\hline Sample & Ar: $\mathrm{C}_{2} \mathrm{H}_{2}$ & RF Power (W) & Time (s) & $\begin{array}{c}\text { Gas flow rate } \\
(\mathrm{sccm})\end{array}$ \\
\hline 1 & $1: 1$ & 600 & 30 & 30 \\
2 & $1: 2$ & 600 & 30 & 30 \\
3 & $2: 1$ & 600 & 30 & 30 \\
4 & $3: 1$ & 600 & 30 & 30 \\
5 & $1: 2$ & 600 & 10 & 30 \\
6 & $1: 2$ & 600 & 20 & 30 \\
7 & $1: 2$ & 600 & 60 & 30 \\
8 & $1: 2$ & 300 & 30 & 30 \\
9 & $1: 2$ & 900 & 30 & 30 \\
10 & $1: 2$ & 1200 & 30 & 30 \\
$11^{*}$ & - & - & - & - \\
\hline
\end{tabular}

*Bank sample.

2.3. Barrier Properties Test Methods. The barrier properties of PET films include oxygen barrier property and water vapor penetration. The oxygen barrier property is tested by VAC-V2 Gas Permeability Tester, and the unit for gas permeability is $\mathrm{cm}^{3} / \mathrm{m}^{2} \cdot 24 \mathrm{~h} \cdot 0.1 \mathrm{MPa}$. The water vapor penetration is tested by W330 water vapor permeability tester, and the unit for water vapor permeability is $\mathrm{g} / \mathrm{m}^{2} \cdot 24 \mathrm{~h}$.

\section{Results and Discussion}

3.1. Surface Morphology Analysis (FESEM). Figure 2 shows the FESEM micrographs of the DLC films on PET. The DLC films deposited at the condition of the RF power $600 \mathrm{~W}$, Ar: $\mathrm{C}_{2} \mathrm{H}_{2}=1: 2$, deposition time $60 \mathrm{~s}$, and gas flow $40 \mathrm{sccm}$. Figure 2 shows that the whole surface of prepared DLC films has a smooth, compact, and uniform microstructure. Also there are few pinholes in the DLC films, which may be caused by insufficient deposition time. Therefore, the uniform microstructure of DLC films is a great help to improve the barrier properties of PET substrate.

3.2. Structure Analysis (Raman). Raman spectrum is commonly used in analyzing molecular structure, which is an effective analytical method to analyze DLC films structure. As we all know, diamond first-order Raman spectra contains a sharp peak at $1332 \mathrm{~cm}^{-1}$, while polycrystalline graphite firstorder Raman spectra has two sharp peaks at $1580 \mathrm{~cm}^{-1}$ and $1358 \mathrm{~cm}^{-1}$, respectively. The Raman spectra of disordered graphite shows two quite sharp modes, the $G$ peak around $1580 \sim 1600 \mathrm{~cm}^{-1}$ and the $D$ peak around $1350 \mathrm{~cm}^{-1}$. G peak corresponds to $s p 2$ lamellae clusters structure, which derives from the stretching vibration of the $\mathrm{C}-\mathrm{C}$ bond in the graphite structure, and this is $\mathrm{E}_{2 \mathrm{~g}}$ mode. $D$ peak corresponds to the structure of disordered graphite boundaries which derives from stretching vibration of a graphite structure called $A_{1 g}$ mode [21,22]. The unusual fact is that $G$ and $D$ peaks, of varying intensity, position, and width, continue to dominate the Raman spectra of nanocrystalline and amorphous carbons, even those without widespread graphitic ordering. The key 


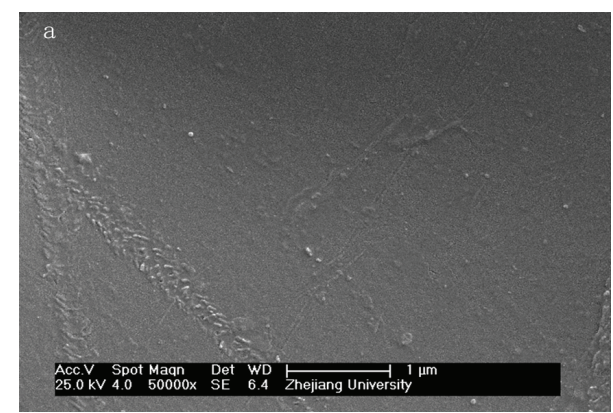

(a)

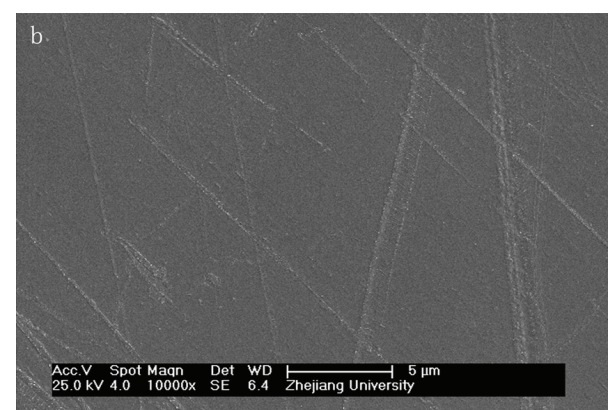

(b)

FIgURe 2: FESEM micrographs of the DLC films on PET.

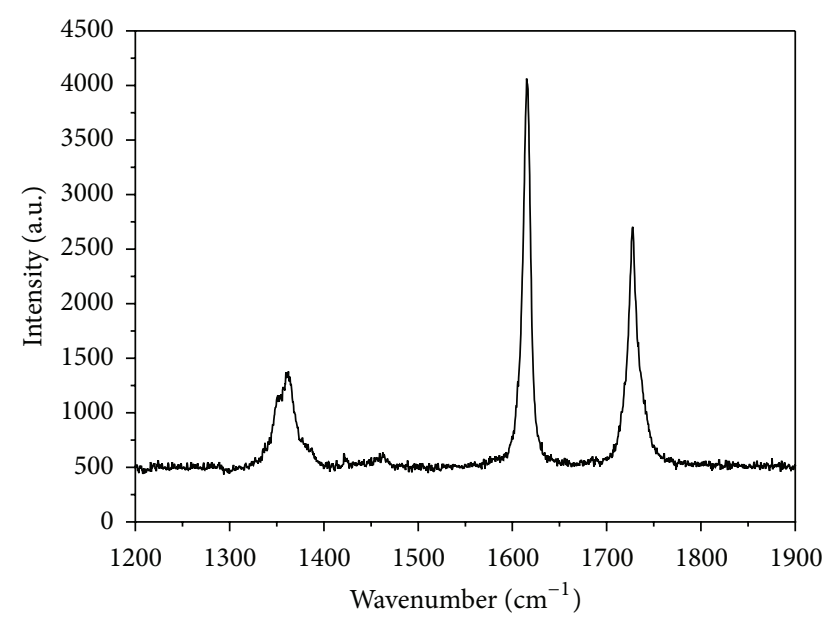

FIgURE 3: Raman spectrum of DLC films on PET.

property of interest in DLC films is the $s p 3$ content. Raman spectroscopy is a valuable method to obtain $s p 3$ content for as-deposited a-C:H, and the $s p 3$ content of DLC films can be deduced from Raman spectroscopy [23].

Figure 3 shows the Raman spectrum of the DLC films on PET. The DLC films deposited at the RF power $300 \mathrm{~W}$, Ar: $\mathrm{C}_{2} \mathrm{H}_{2}=1: 2$, deposition time $60 \mathrm{~s}$, and gas flow $40 \mathrm{sccm}$. Figure 3 shows that there are two distinct peaks in the 1100 $1700 \mathrm{~cm}^{-1}$ range, the $D$ peak of DLC films at $1360 \mathrm{~cm}^{-1}$, and the $G$ peak of DLC films at $1615 \mathrm{~cm}^{-1}$. The areas of $D$ and $G$ peak in the Raman spectrum are corresponding to peak intensity $I_{D}$ and $I_{G}$, respectively [24]. So the ratio of $I_{D} / I_{G}$ is nearly 0.76 according to the Raman spectrum data. The $I_{D} / I_{G}$ ratios of DLC films which prepared on different process conditions are shown in Table 2.

Figure 4 shows the sample's oxygen permeability and water vapor permeability curves under different $I_{D} / I_{G}$ ratios. Figure 4 shows that the smaller the $I_{D} / I_{G}$ ratio is, the higher the barrier properties of DLC films are. The reason is that when the $I_{D} / I_{G}$ ratio decreases, the content of $s p 3$ bond in the DLC films increases. Since the $s p 3$ bond is the representative of diamond-like structure, the increasing of $s p 3$ content means the increasing of the content of diamondlike structure in the DLC films, so the barrier properties

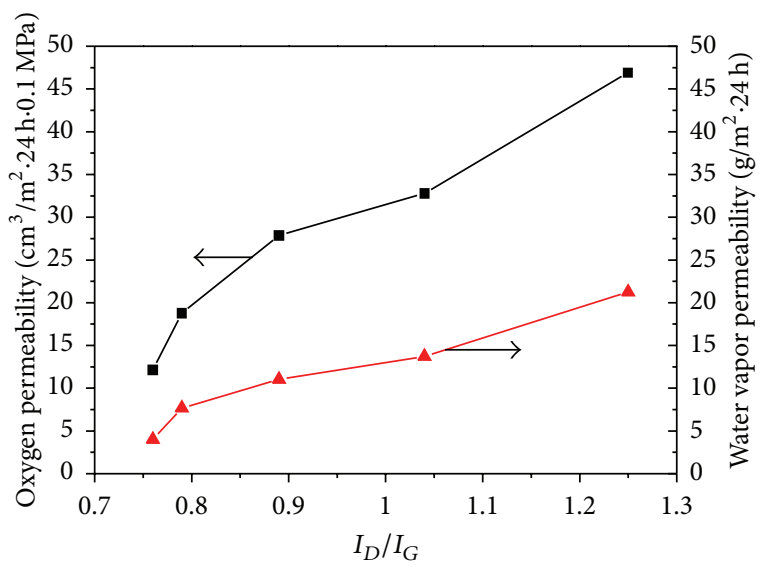

Figure 4: Barrier properties under different $I_{D} / I_{G}$ ratios.

have been enhanced. When the $I_{D} / I_{G}$ ratio is more than $0.8 \sim 0.9$, the barrier properties of DLC films are improved slowly; while the $I_{D} / I_{G}$ ratio is less than $0.8 \sim 0.9$, the barrier properties of DLC films are improved rapidly. The physical properties of carbon materials are strong dependent on the ratio of $s p 2$ (graphite-like) to $s p 3$ (diamond-like) bonds. Then according to the literature [23], the $s p 3$ content is nearly 0.4 when the ratio of $I_{D} / I_{G}$ is nearly 0.76 . Therefore the barrier properties have been greatly improved when the $s p 3$ content increases.

From the results of Raman spectrum, we can conclude that the DLC films has been deposited on the surface of PET film, its structure fall within the range between that of diamond and graphite. The DLC films are an amorphous carbon films which mixed with $s p 3$ bond and $s p 2$ bond.

3.3. Barrier Properties Analysis. Samples have been prepared under different conditions, and their oxygen permeability and water vapor permeability experimental test results are shown in Table 3. From Table 3, we can see that the condition of sample 2 is a group of optimal experimental conditions. Thus the best oxygen barrier property and water vapor barrier property of PET films are increased by 11 times and 12 times, respectively, when the DLC films deposited at the RF power $600 \mathrm{~W}, \mathrm{Ar}: \mathrm{C}_{2} \mathrm{H}_{2}=1: 2$, deposition time $30 \mathrm{~s}$ and gas flow 
TABLE 2: $I_{D} / I_{G}$ ratios under different process conditions.

\begin{tabular}{lcccccc}
\hline Ar: $\mathrm{C}_{2} \mathrm{H}_{2}$ & $\begin{array}{c}\text { RF power } \\
(\mathrm{W})\end{array}$ & Time $(\mathrm{s})$ & $\begin{array}{c}\text { Gas flow rate } \\
(\mathrm{sccm})\end{array}$ & $\begin{array}{c}\text { Oxygen permeability } \\
\left(\mathrm{cm}^{3} / \mathrm{m}^{2} \cdot 24 \mathrm{~h} \cdot 0.1 \mathrm{MPa}\right)\end{array}$ & $\begin{array}{c}\text { Water vapor permeability } \\
\left(\mathrm{g} / \mathrm{m}^{2} \cdot 24 \mathrm{~h}\right)\end{array}$ & $\begin{array}{l}I_{D} / I_{G} \text { ratio } \\
1: 2\end{array}$ \\
\hline 600 & 30 & 30 & 12.16 & 4.01 & 0.76 \\
$1: 2$ & 900 & 30 & 30 & 18.76 & 11.03 & 0.79 \\
$1: 2$ & 600 & 20 & 30 & 27.89 & 32.78 & 0.89 \\
$2: 1$ & 600 & 30 & 30 & 46.91 & 21.25 & 1.04 \\
$3: 1$ & 600 & 30 & 30 & & & 1.25 \\
\hline
\end{tabular}

TABLE 3: Barrier properties under different deposition process.

\begin{tabular}{|c|c|c|c|c|c|c|}
\hline Sample & Ar: $\mathrm{C}_{2} \mathrm{H}_{2}$ & RF power $(W)$ & Time (s) & $\begin{array}{l}\text { Gas flow rate } \\
(\mathrm{sccm})\end{array}$ & $\begin{array}{l}\text { Oxygen permeability } \\
\left(\mathrm{cm}^{3} / \mathrm{m}^{2} \cdot 24 \mathrm{~h} \cdot 0.1 \mathrm{MPa}\right)\end{array}$ & $\begin{array}{l}\text { Water vapor permeability } \\
\left(\mathrm{g} / \mathrm{m}^{2} \cdot 24 \mathrm{~h}\right)\end{array}$ \\
\hline 1 & $1: 1$ & 600 & 30 & 30 & 22.41 & 11.56 \\
\hline 2 & $1: 2$ & 600 & 30 & 30 & 12.16 & 4.01 \\
\hline 3 & $2: 1$ & 600 & 30 & 30 & 32.78 & 13.73 \\
\hline 4 & $3: 1$ & 600 & 30 & 30 & 46.91 & 21.25 \\
\hline 5 & $1: 2$ & 600 & 10 & 30 & 43.91 & 16.07 \\
\hline 6 & $1: 2$ & 600 & 20 & 30 & 27.89 & 11.03 \\
\hline 7 & $1: 2$ & 600 & 60 & 30 & 19.01 & 8.15 \\
\hline 8 & $1: 2$ & 300 & 30 & 30 & 24.37 & 9.16 \\
\hline 9 & $1: 2$ & 900 & 30 & 30 & 18.76 & 7.69 \\
\hline 10 & $1: 2$ & 1200 & 30 & 30 & 26.12 & 14.57 \\
\hline $11^{*}$ & - & - & - & - & 135.98 & 48.76 \\
\hline
\end{tabular}

*Bank sample.

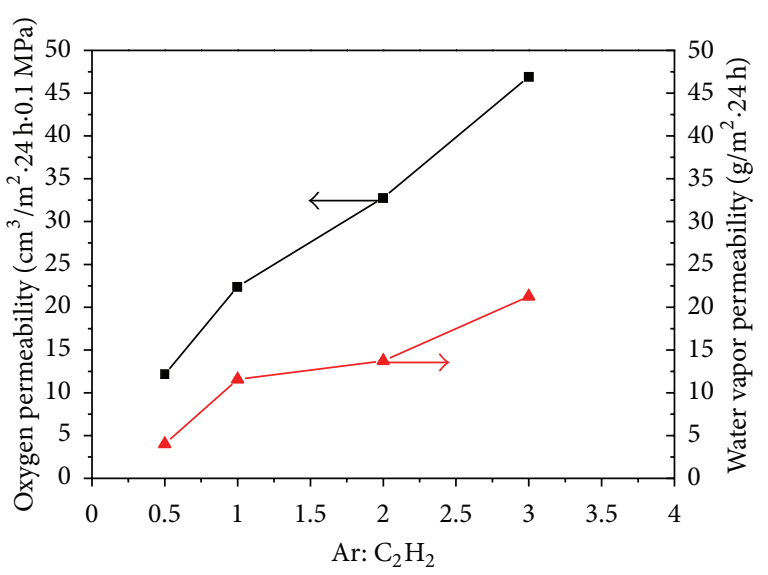

Figure 5: Barrier properties under different $\mathrm{Ar}: \mathrm{C}_{2} \mathrm{H}_{2}$.

$30 \mathrm{sccm}$, in which the $I_{D} / I_{G}$ ratio of the DLC film is nearly 0.76 , and the $s p 3$ content is about $40 \%$.

Figure 5 shows that the $\mathrm{Ar} / \mathrm{C}_{2} \mathrm{H}_{2}$ ratio has an effect on the oxygen permeability and water vapor permeability of DLC films. From the Figure 5 we can see that, with the increase of $\mathrm{Ar} / \mathrm{C}_{2} \mathrm{H}_{2}$ ratio, the oxygen and water vapor permeation increase. When the $\mathrm{Ar} / \mathrm{C}_{2} \mathrm{H}_{2}$ ratio is $1 / 2$, the two gas permeations reach the minimum value. On the one hand, the more the Ar content is, the more the collision probability of particles and electron is, the higher the energy of particles is. High particle energy allows the $s p 3$ bond to shift to the stable $s p 2$ bond [25]. Since the $s p 3$ bond is the representative of diamond-like structure, the decreasing of $s p 3$ content means the decreasing of the content of diamondlike structure in the DLC films, so the barrier properties deteriorate. On the other hand, the more the $\mathrm{C}_{2} \mathrm{H}_{2}$ content is, the more the reactive groups in the reaction atmosphere are, the higher the growth rate of DLC films is, the better the barrier properties are.

Figure 6 shows that the deposition time has an effect on the oxygen permeability and water vapor permeability of DLC films. From Figure 6, we can see that, with the increase of deposition time, the oxygen and water vapor permeation decrease first and then begin to increase, but there are significant differences in the degree of change. When the deposition time is less than $30 \mathrm{~s}$, the gas permeations are decreased rapidly. When the deposition time is more than $30 \mathrm{~s}$, the permeations are increased smoothly. When the deposition time is $30 \mathrm{~s}$, the two gas permeations reach the minimum value. The more the deposition time is, the more the amount of amorphous carbon materials is, the higher the barrier properties are. However, with a further increase of the deposition time, the surface temperature of the film is increased, and it allows the $s p 3$ bond to shift to $s p 2$ bond [25]. Meanwhile the thickness of PET substrate only has $0.1 \mathrm{~mm}$, with the continue increase of deposition time, it will destroy the PET substrate which leads to reducing the sample's barrier properties. 


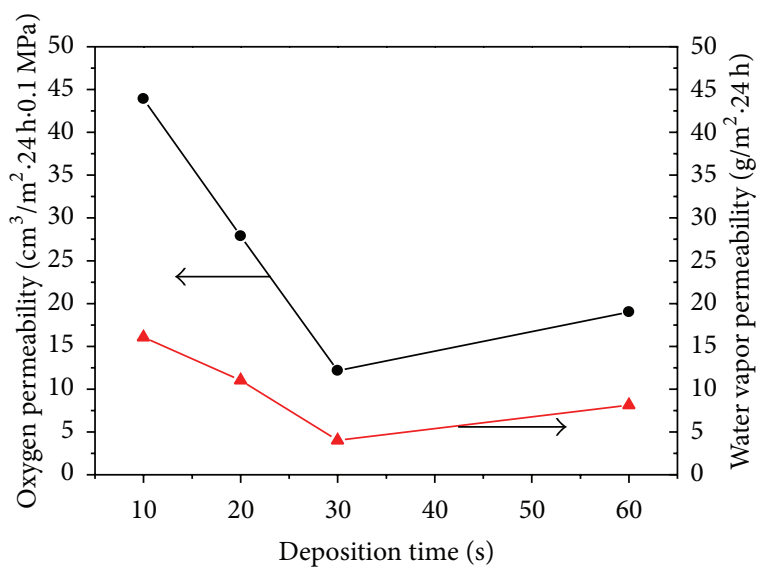

FiguRE 6: Barrier properties under different deposition time.

Figure 7 shows that the RF power has an effect on the oxygen permeability and water vapor permeability of DLC films. From Figure 7 we can see that, with the increase of $\mathrm{RF}$ power, the oxygen and water vapor permeation decrease first and then begin to increase the changes are all obvious. When the RF power is $600 \mathrm{~W}$, the two gas permeations reach the minimum value. In the initial period, the higher the RF power is, the higher the growth rate of DLC films is, the more the amount of amorphous carbon materials is, the better the barrier properties are. However, with a further increase of RF power, the energy of particles increases which improves its ability of bombarding on the substrate; this allows the surface temperature of the film increases and the $s p 3$ bond to shift to $s p 2$ bond [25]. The decreasing of $s p 3$ content means the decreasing of the content of diamond-like structure in the DLC films, so the barrier properties deteriorate.

\section{Conclusion}

In this paper, the DLC films deposited on the PET surface by PECVD technology are successfully obtained. Through observing and analyzing the process parameters, surface and internal structures of the DLC films, we can obtain the following conclusions.

(1) Take $\mathrm{C}_{2} \mathrm{H}_{2}$ as a carbon source, Ar as a diluent gas; a layer of DLC films with excellent barrier properties can deposit on the surface of PET film by using the PECVD technology.

(2) Surface morphology and the internal structure of DLC films are investigated by using Raman and FESEM. The surface and internal structures of DLC films are closely related to deposition process parameters. The results show that the diamond-like carbon films prepared by PECVD system are an amorphous carbon films which mixed with $s p 3$ bond and $s p 2$ bond. The smaller the $I_{D} / I_{G}$ ratio is, the more the $s p 3$ content is, the higher the barrier properties of DLC films are.

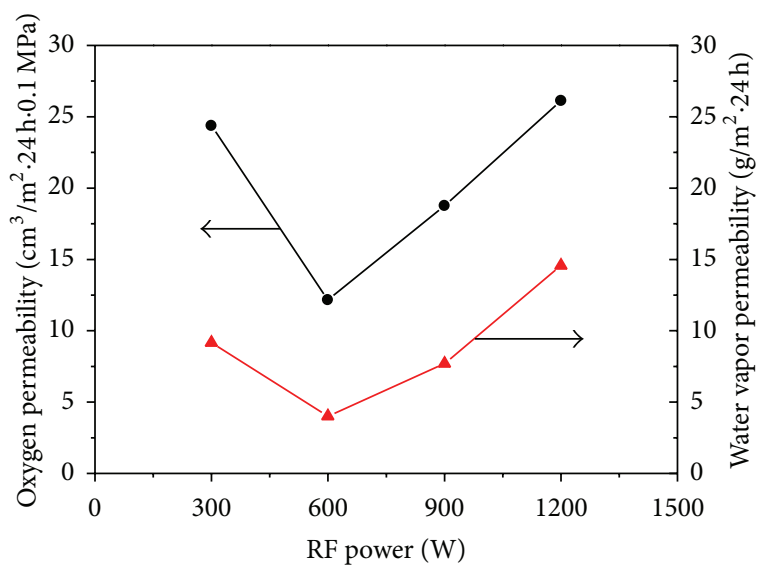

FIGURE 7: Barrier properties under different RF power.

(3) The barrier properties of PET films which have been deposited the DLC films are tested. The results show that the deposition process parameters have an important effect on structure and performance of DLC films. Compared with untreated PET film, the barrier properties of the treated PET are improved obviously. The best oxygen barrier property and water vapor barrier property of PET films are increased by 11 times and 12 times, respectively, when the DLC films deposited at the RF power $600 \mathrm{~W}, \mathrm{Ar}: \mathrm{C}_{2} \mathrm{H}_{2}=1: 2$, deposition time $30 \mathrm{~s}$, and gas flow $30 \mathrm{sccm}$, in which the $I_{D} / I_{G}$ ratio of the DLC film is nearly 0.76 , and the sp3 content is about $40 \%$.

\section{Acknowledgments}

This work was financially supported by the National Natural Science Foundation of China (51206148, 51106140) and Zhejiang Provincial Natural Science Foundation of China (YY1110642, Y407311).

\section{References}

[1] J. Li, C. Gong, X. Tian, S. Yang, R. K. Y. Fu, and P. K. Chu, "Structure and gas-barrier properties of amorphous hydrogenated carbon films deposited on inner walls of cylindrical polyethylene terephthalate by plasma-enhanced chemical vapor deposition," Applied Surface Science, vol. 255, no. 7, pp. 39833988, 2009.

[2] N. Boutroy, Y. Pernel, J. M. Rius et al., "Hydrogenated amorphous carbon film coating of PET bottles for gas diffusion barriers," Diamond and Related Materials, vol. 15, no. 4-8, pp. 921-927, 2006.

[3] P. B. Yang, Y. Zheng, B. Zhang, and L. Wei, "The hightemperature tribological properties of Si-DLC films," Surface and Interface Analysis, vol. 44, no. 13, pp. 1601-1605, 2012.

[4] L. Valentini, J. M. Kenny, G. Mariotto et al., "Ar-dilution effects on the elastic and structural properties of hydrogenated hard carbon films deposited by plasma-enhance chemical vapor deposition," Diamond and Related Materials, vol. 10, no. 3-7, pp. 1088-1092, 2001. 
[5] B. J. Jones, S. Wright, R. C. Barklie, J. Tyas, J. Franks, and A. J. Reynolds, "Nanostructure and paramagnetic centres in diamond-like carbon: effect of Ar dilution in PECVD process," Diamond and Related Materials, vol. 17, no. 7-10, pp. 1629-1632, 2008.

[6] N. Dwivedi, S. Kumar, H. K. Malik, G. Govind, C. M. S. Rauthan, and O. S. Panwar, "Correlation of sp3 and sp2 fraction of carbon with electrical, optical and nano-mechanical properties of argon-diluted diamond-like carbon films," Applied Surface Science, vol. 257, no. 15, pp. 6804-6810, 2011.

[7] X. D. Yang, T. Saito, Y. Nakamura, Y. Kondo, and N. Ohtake, "Mechanical properties of DLC films prepared inside of microholes by pulse plasma CVD," Diamond and Related Materials, vol. 13, no. 11-12, pp. 1984-1988, 2004.

[8] P. Papakonstantinou, J. F. Zhao, P. Lemoine, E. T. McAdams, and J. A. McLaughlin, "The effects of Si incorporation on the electrochemical and nanomechanical properties of DLC thin films," Diamond and Related Materials, vol. 11, no. 3-6, pp. 10741080, 2002.

[9] A. P. Mousinho, R. D. Mansano, M. Massi, and L. S. Zambom, "High density plasma chemical vapor deposition of diamondlike carbon films," Microelectronics Journal, vol. 34, no. 5-8, pp. 627-629, 2003.

[10] T. Kuzumaki, Y. Obara, Y. Ishiyama, R. Sato, M. Takashima, and N. Ohtake, "Tensile strength of DLC films evaluated by a nanomaterials testing system," Diamond and Related Materials, vol. 25, no. 6, pp. 1-4, 2012.

[11] B. J. Jones and J. J. Ojeda, "Substrate and material transfer effects on the surface chemistry and texture of diamond-like carbon deposited by plasma-enhanced chemical vapour deposition," Surface and Interface Analysis, vol. 44, no. 8, pp. 1187-1192, 2012.

[12] V. M. Elinson, V. V. Sleptsov, A. N. Laymin, V. V. Potraysay, L. N. Kostuychenko, and A. D. Moussina, "Barrier properties of carbon films deposited on polymer-based devices in aggressive environments," Diamond and Related Materials, vol. 8, no. 12, pp. 2103-2109, 1999.

[13] J. Takahashi and A. Hotta, "Adhesion enhancement of polyolefins by diamond like carbon coating and photografting polymerization," Diamond and Related Materials, vol. 26, pp. 55-59, 2012.

[14] J. Choi, K. Ishii, T. Kato, M. Kawaguchi, and W. Lee, "Structural and mechanical properties of DLC films prepared by bipolar PBII\&D," Diamond and Related Materials, vol. 20, no. 5-6, pp. 845-848, 2011.

[15] B. Saha, E. Liu, S. B. Tor, D. E. Hardt, J. H. Chun, and N. W. Khun, "Improvement in lifetime and replication quality of $\mathrm{Si}$ micromold using N:DLC:Ni coatings for microfluidic devices," Sensors and Actuators B, vol. 150, no. 1, pp. 174-182, 2010.

[16] S. Nagashima, T. Hasebe, D. Tsuya et al., "Controlled formation of wrinkled diamond-like carbon (DLC) film on grooved poly(dimethylsiloxane) substrate," Diamond and Related Materials, vol. 22, pp. 48-51, 2012.

[17] R. Scaffaro and A. Maio, "Enhancing the mechanical performance of polymer based nanocomposites by plasmamodification of nanoparticles," Polymer Testing, vol. 31, pp. 889894, 2012.

[18] M. Agemi, K. Kayama, M. Noborisaka, Y. Tachimoto, A. Shirakura, and T. Suzuki, "Synthesis of hydrogenated amorphous carbon films with a line type atmospheric-pressure plasma CVD apparatus," Surface and Coatings Technology, vol. 206, no. 7, pp. 2025-2029, 2011.
[19] D. Xie, H. Liu, X. Deng, Y. X. Leng, and N. Huang, "Effects of process parameters on the structure of hydrogenated amorphous carbon films processed by electron cyclotron resonance plasma enhanced chemical vapor deposition," Surface and Coatings Technology, vol. 204, no. 18-19, pp. 3029-3033, 2010.

[20] R. Maheswaran, R. Sivaraman, O. Mahapatra, P. C. Rao, C. Gopalakrishnan, and D. J. Thiruvadigal, "Surface studies of diamond-like carbon films grown by plasma-enhanced chemical vapor deposition," Surface and Interface Analysis, vol. 42, no. 12-13, pp. 1702-1705, 2010.

[21] E. Sagnes, J. Szurmak, D. Manage, and S. Zukotynski, "Structure of hydrogenated amorphous carbon deposited using saddlefield glow-discharge in methane," Journal of Non-Crystalline Solids, vol. 249, no. 1, pp. 69-79, 1999.

[22] R. W. Lamberton, S. M. Morley, P. D. Maguire, and J. A. McLaughlin, "Monitoring laser-induced microstructural changes of thin film hydrogenated amorphous carbon (a-C:H) using Raman spectroscopy," Thin Solid Films, vol. 333, no. 1-2, pp. 114-125, 1998.

[23] A. C. Ferrari and J. Robertson, "Interpretation of Raman spectra of disordered and amorphous carbon," Physical Review B, vol. 61, no. 20, pp. 14095-14107, 2000.

[24] L. Zhu, M.-F. Jiang, Z.-Y. Ning, J.-L. Du, and P.-J. Wang, "Hydrophobic nature of fluorinated diamond-like carbon films prepared under different radio-frequency power," Acta Physica Sinica, vol. 58, no. 9, pp. 6430-6435, 2009.

[25] H. X. Xie, G. Ling, and Z. T. Zhu, "Structure and properties of the DLC films deposited By RF-PECVD process," Journal of Materials Science and Engineering, vol. 27, no. 2, pp. 190-194, 2009 (Chinese). 

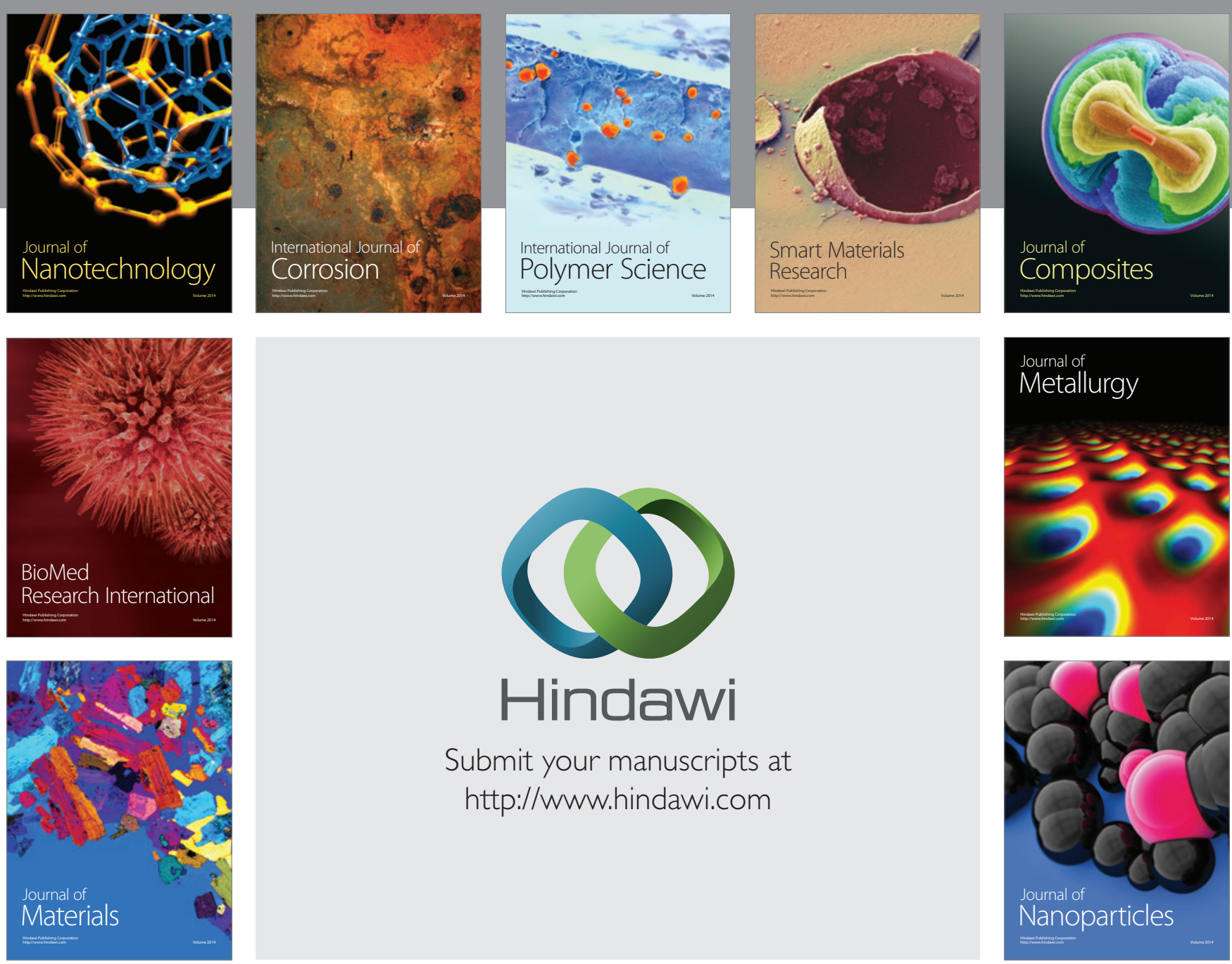

Submit your manuscripts at http://www.hindawi.com
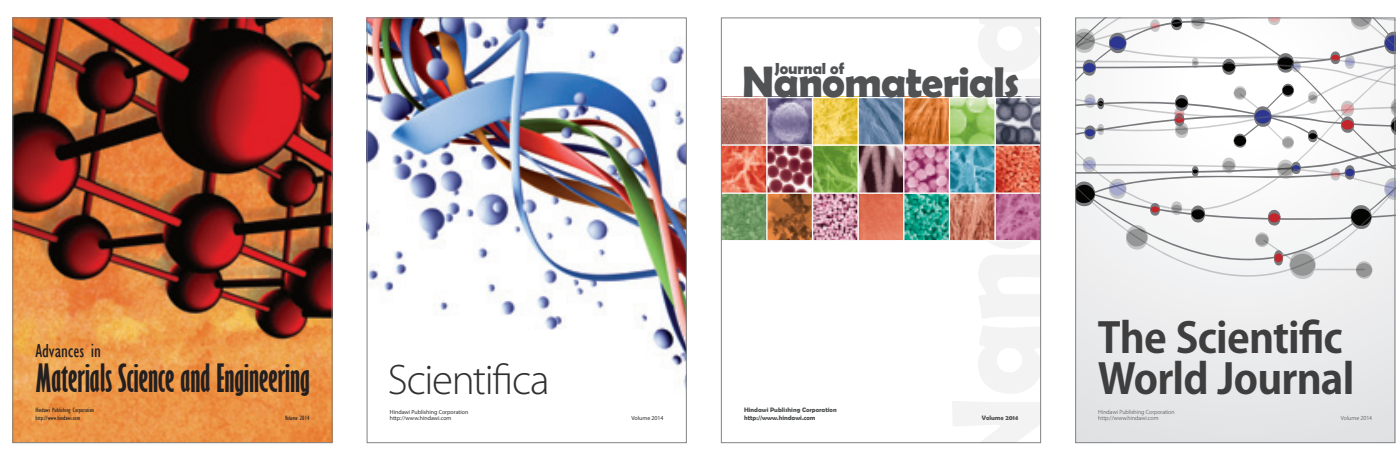

\section{The Scientific World Journal}
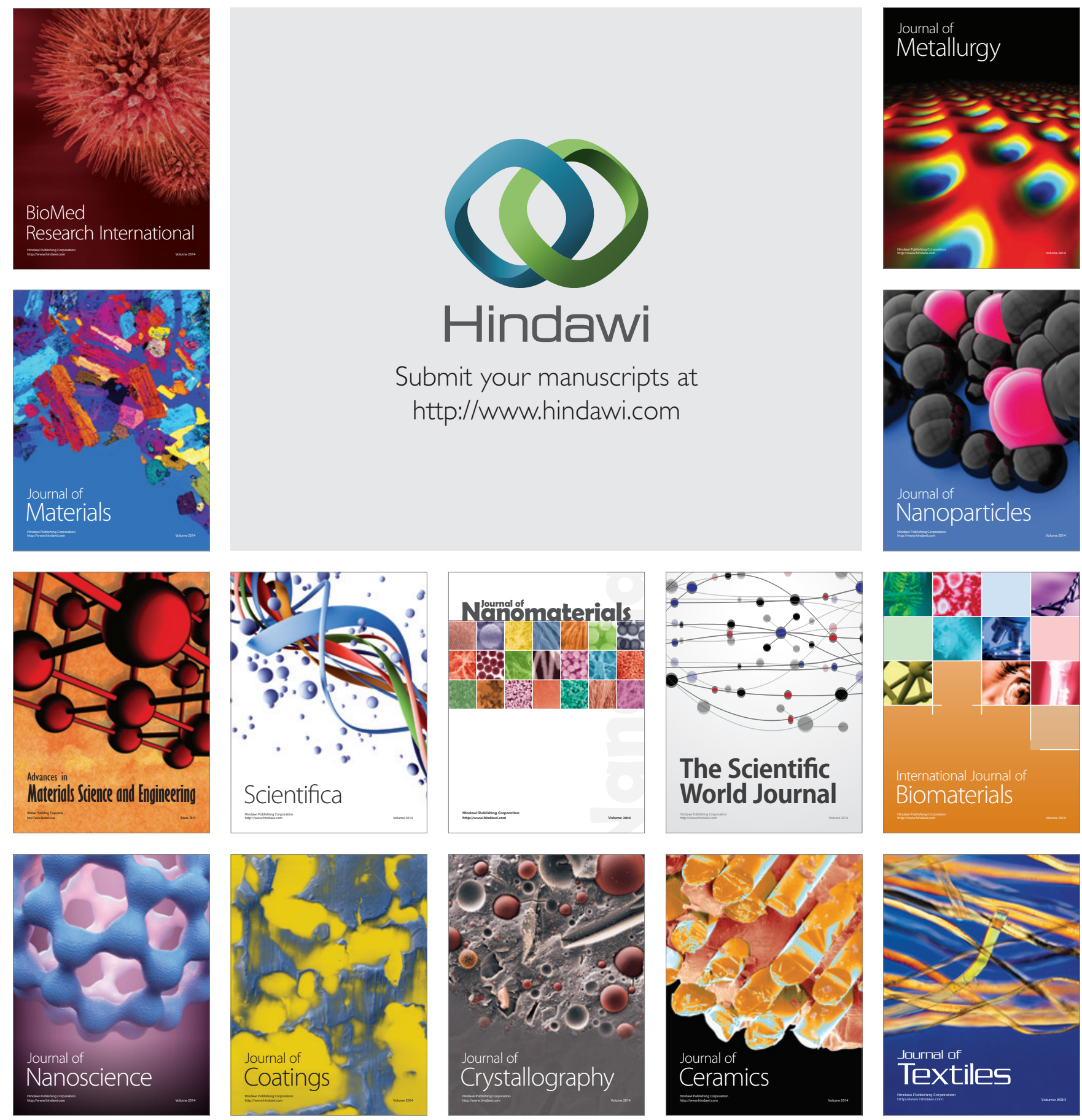